\title{
Diagnosis and Treatment of Parasellar Lesions
}

\author{
Federico Gatto ${ }^{\text {a }}$ Luis G. Perez-Rivas ${ }^{\text {b Nicoleta Cristina Olarescu }}{ }^{c, 1}$ \\ Pati Khandeva $^{d}$ Konstantina Chachlaki ${ }$ Giampaolo Trivellin ${ }^{f}$ \\ Manuel D. Gahete ${ }^{g-j}$ Thomas Cuny ${ }^{k}$ on behalf of the ENEA Young Researchers
}

Committee (EYRC)

aEndocrinology Unit, Department of Specialist Medicine, IRCCS Ospedale Policlinico San Martino, Genoa, Italy;

${ }^{b}$ Medizinische Klinik und Poliklinik IV, Ludwig-Maximilians-Universität (LMU) München, Munich, Germany; ' Section

of Specialized Endocrinology, Department of Endocrinology, Medical Clinic, Oslo University Hospital, and University of Oslo, Oslo, Norway; ${ }^{\mathrm{d}}$ Endocrinology Research Center, Moscow, Russia; ${ }^{\mathrm{e}}$ Inserm, Laboratory of Development and Plasticity of the Neuroendocrine Brain, Jean-Pierre Aubert Research Centre, UMR-S 1172, Lille, France; fSection on Endocrinology and Genetics, Eunice Kennedy Shriver National Institute of Child Health and Human Development, National Institutes of Health, Bethesda, MD, USA; ${ }^{9}$ Maimónides Institute of Biomedical Research of Córdoba (IMIBIC), Córdoba, Spain; hepartment of Cell Biology, Physiology and Immunology, University of Córdoba, Córdoba, Spain; i Reina Sofía University Hospital, Córdoba, Spain; ${ }^{j} \mathrm{CIBER}$ Pathophysiology of Obesity and Nutrition (CIBERobn), Córdoba, Spain; ${ }^{k}$ Department of Endocrinology, Hospital La Conception, Aix Marseille University, APHM, INSERM, MMG, Marseille, France; 'Department of Medical Biochemistry, Oslo University, Oslo, Norway

\section{Keywords}

Cavernous sinus · Craniopharyngioma · Meningioma .

Parasellar region Pituitary

\begin{abstract}
The parasellar region, located around the sella turcica, is an anatomically complex area representing a crossroads for important adjacent structures. Several lesions, including tumoral, inflammatory vascular, and infectious diseases may affect this area. Although invasive pituitary tumors are the most common neoplasms encountered within the parasellar region, other tumoral (and cystic) lesions can also be detected. Craniopharyngiomas, meningiomas, as well as Rathke's cleft cysts, chordomas, and ectopic pituitary tumors can pri-
\end{abstract}

karger@karger.com www.karger.com/nen

(C) 2020 S. Karger AG, Basel

Karger! marily originate from the parasellar region. Except for hormone-producing ectopic pituitary tumors, signs and symptoms of these lesions are usually nonspecific, due to a mass effect on the surrounding anatomical structures (i.e., headache, visual defects), while a clinically relevant impairment of endocrine function (mainly anterior hypopituitarism and/ or diabetes insipidus) can be present if the pituitary gland is displaced or compressed. Differential diagnosis of parasellar lesions mainly relies on magnetic resonance imaging, which should be interpreted by neuroradiologists skilled in base skull imaging. Neurosurgery is the main treatment, alone or in combination with radiotherapy. Of note, recent studies have identified gene mutations or signaling pathway modulators that represent potential candidates for the development of targeted therapies, particularly for craniopharyngio- 
mas and meningiomas. In summary, parasellar lesions still represent a diagnostic and therapeutic challenge. A deeper knowledge of this complex anatomical site, the improvement of imaging tools, as well as novel insights into the pathophysiology of presenting lesions are strongly needed to improve the management of parasellar lesions.

(c) 2020 S. Karger AG, Base

\section{Introduction}

The parasellar region, located immediately around the sella turcica, is an anatomically complex area representing a crucial crossroads for important adjacent structures [1]. In a simplified representation, parasellar region is limited laterally by the cavernous sinuses (CS) on both sides of the sella turcica, above by the optic chiasm and below by the sphenoidal sinus. Other structures, such as the meninges, blood vessels, and the hypothalamic-pituitary system can be considered part of this wide area, which is not clearly delineated, and could therefore be affected by all the different lesions possibly developing from these structures [2]. Consequently, signs and symptoms of parasellar lesions are mainly related to a mass effect on the surrounding anatomical structures (i.e., headache, visual defects) but, if the pituitary gland is affected, endocrine functions can be severely impaired as well.

In the present article, we aim to provide an overview of the lesions encountered in the parasellar region, with a particular description of the key clinical and radiological features that characterized them. Finally, the recent advances on the new molecular actors playing a role in the pathophysiology of parasellar lesions will be discussed.

\section{Anatomy of the Parasellar Region}

The parasellar region defines a complex anatomical area because of its small size while containing an impressive amount of neural and vascular structures, such as the CS. The CS are paired, symmetric, trabeculated venous sinuses, delimitated by dural walls and containing the sympathic plexus, the cranial nerves, and the intracavernous portion of the internal carotid artery (Fig. 1) [3]. The sinus is the site of a venous confluence that receives the terminal end of multiple veins draining the orbit, the sylvian fissure as well as the middle and anterior fossae. Furthermore, the CS has free communication with the basilar, superior, inferior petrosal, and intercavernous sinuses [4].

Diagnosis and Treatment of Parasellar Lesions

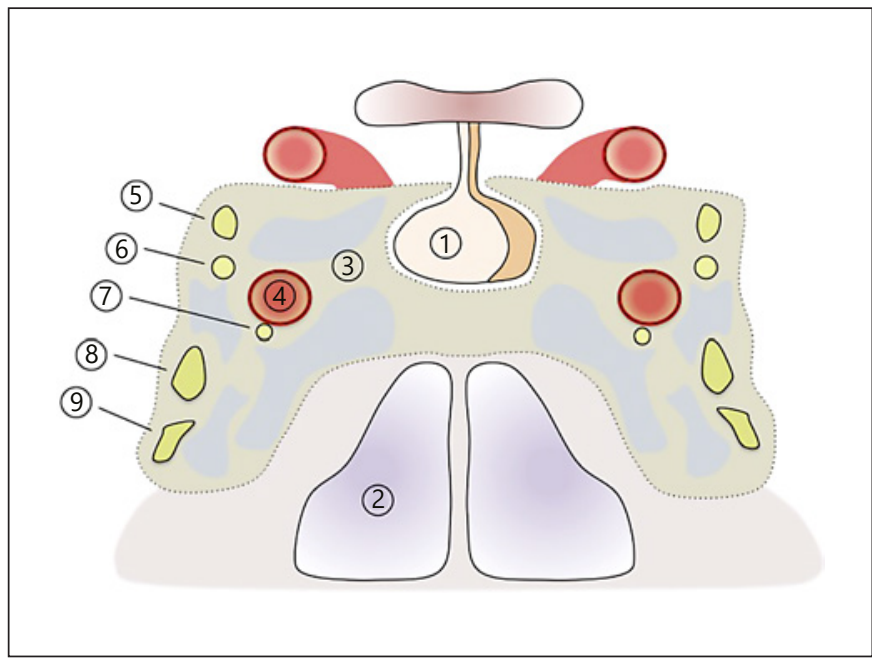

Fig. 1. Schematic representation of the sellar region. Coronal section showing the pituitary gland (1), the sphenoidal sinus (2), and the parasellar region containing the cavernous sinus (3). In the cavernous sinus, the oculomotor nerve (III) (5) lies superiorly followed by the trochlear nerve (IV) (6) and the ophthalmic branch (8) and the maxillary branch of trigeminal nerve (V) (9). The abducens nerve (VI) (7) lies in the cavernous sinus abutting the lateral wall of the intracavernous carotid artery (4).

The oculomotor nerve lies superiorly between the two dural leaves of the lateral sinus wall, and the trochlear nerve and the ophthalmic branch of the trigeminal nerve are successively found from the top to the bottom of CS. The abducens nerve lies in the CS abutting the lateral wall of the carotid artery and the medial side of the ophthalmic nerve. Whether the maxillary branch of the trigeminal nerve is intracavernous or extracavernous is a source of debate; however, its close proximity results in its compression in many parasellar pathologies. The lateral dural reflection of these sinuses is easily visualized on magnetic resonance imaging (MRI), but a clear visualization of the thin medial dural wall that separates the sinus from the outer periosteal layer of the pituitary gland is often problematic. The intracavernous carotid artery (ICA) has a $\mathrm{C}$-shaped curve as it traverses the CS and carries with it the sympathetic carotid plexus that usually sends fibers to the abducens nerve. It is possible to visualize the meningohypophyseal artery and its branches by displacing the carotid artery laterally [5].

Due to their anatomical complexity, CS are difficult to approach by surgery, and an a priori decision with regard to the radicality of the tumor resection that takes into account both the risks and the benefits for the patient is needed. 
Fig. 2. Meningioma of the right cavernous sinus with intrasellar extension. a Coronal T2. Bulging of the lateral wall of the right cavernous sinus and convexity of the upper pole of the sellar component (blue arrow). The meningioma is discretely hyperintense as compared to the grey matter of the temporal lobe (yellow arrow). b Coronal contrast-enhanced T1 showing a severe reduction of the right ICA lumen (blue arrow) as compared to the other side. Courtesy of Prof. Jean-François Bonneville.
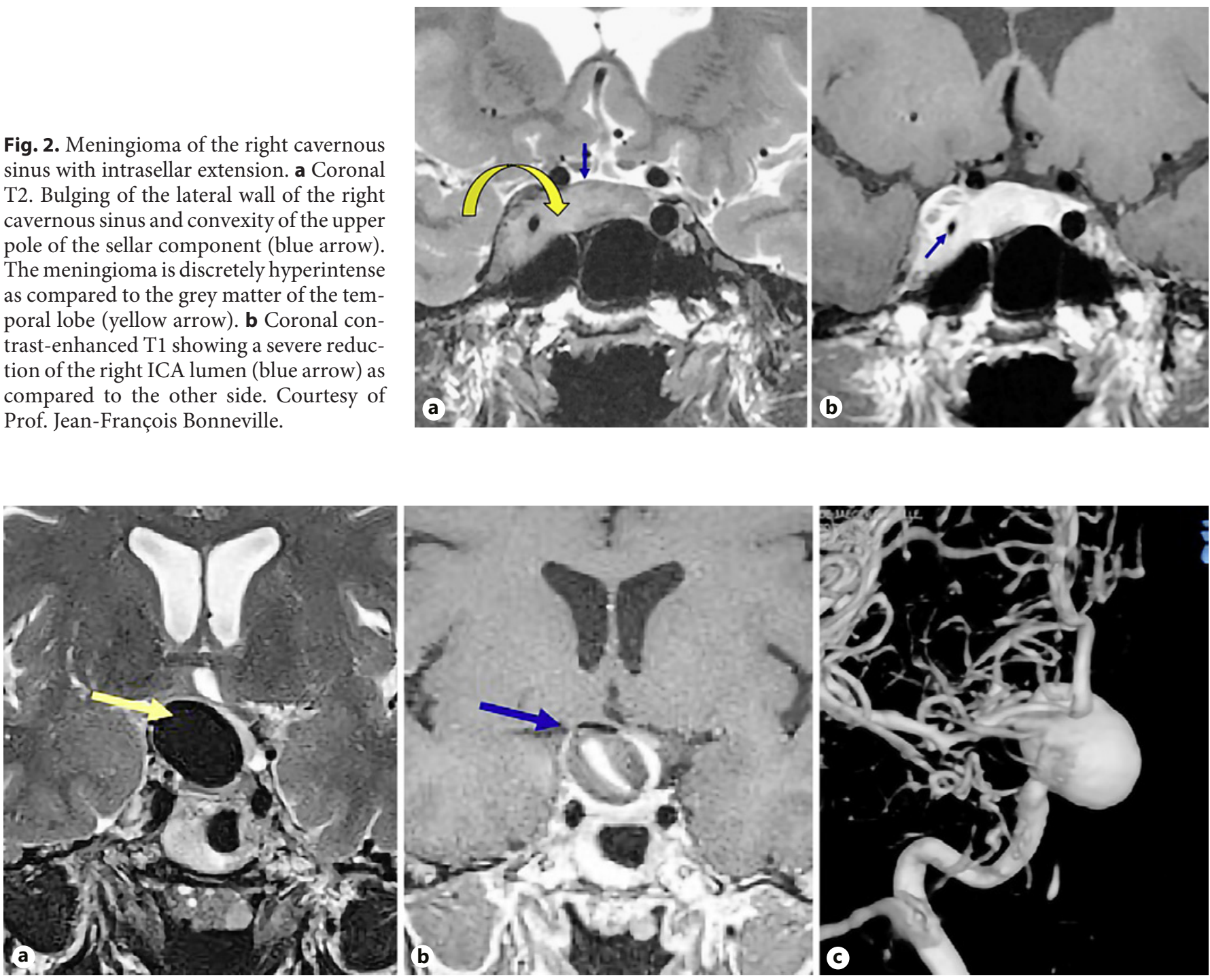

Fig. 3. Right internal carotid artery thrombosed aneurysm in its supraclinoid segment. a Coronal T2 showing a well-circumscribed, strong hypointense lesion (yellow arrow), which can mimic a tumor of the parasellar and/or suprasellar region. b Coronal contrast-enhanced T1 with peripheral unenhanced layers of thrombus (blue arrow) and a patent enhanced portion of the lumen of the aneurysm in the center. c 3D rendering reformatted MR angiogram. Courtesy of Prof. Jean-François Bonneville.

\section{Sellar or Parasellar Region: Imaging Considerations}

MRI represents the exam of choice to investigate the sellar region. In spite of its high spatial resolution, it cannot systematically provide the accurate origin of a lesion, making sometimes the etiological diagnosis unsure, and so even more the therapeutic strategy. A step-by-step analysis is therefore mandatory and consists, first, in identification of the pituitary gland, stalk, and the sella turcica [6]. Afterwards, the epicenter of the lesion has to be determined (cranial, distal, or lateral to the sella). An enlargement of the sella can help to specify the pituitary origin of the lesion. In a third step, the analysis of signal intensity is determinant to clarify the nature of the lesion (i.e., cystic or solid) and identify the different structures contained in the CS (fat, vessels, and nerves). ICAs present a hyposignal in $\mathrm{T} 1$ and $\mathrm{T} 2$ related to fast flow (also known as the "flow void"). Of note, CS invasive pituitary tumors (PTs) usually do not exert a mass effect on the lumen of the ICA, while tumors that primarily originate 
Table 1. Overview of the lesions in the cavernous sinus

\begin{tabular}{|c|c|c|c|}
\hline Tumoral lesions & Vascular lesions & Inflammatory lesions & Cystic lesions \\
\hline $\begin{array}{l}\text { Intracavernous } \\
\text { Meningioma } \\
\text { Schwannoma } \\
\text { Neurofibroma } \\
\text { Lymphoma } \\
\text { Metastasis } \\
\text { Paracavernous } \\
\text { Adenoma } \\
\text { Chordoma } \\
\text { Chondrosarcoma } \\
\text { ENT carcinoma } \\
\text { Paraganglioma } \\
\text { Juvenile nasopharyngeal angiofibroma }\end{array}$ & $\begin{array}{l}\text { Aneurysm } \\
\text { Cavernous hemangioma } \\
\text { Carotid cavernous fistula } \\
\text { Thrombosis }\end{array}$ & $\begin{array}{l}\text { Tolosa-Hunt syndrome } \\
\text { Sarcoidosis } \\
\text { Granulomatosis with polyangiitis } \\
\text { (Wegener's) } \\
\text { Infection/tuberculoma }\end{array}$ & $\begin{array}{l}\text { Epidermoid cyst } \\
\text { Dermoid cyst } \\
\text { Arachnoid cyst }\end{array}$ \\
\hline
\end{tabular}

from the CS and invade the pituitary sella can collapse the lumen of the ICA as observed in CS meningioma (Fig. 2). Moreover, a tissue that has identical MR signals and enhancement as those of the intrasellar component of the tumor is highly indicative of a primary tumor originating from the sella (i.e., invasive PT). In this scenario, it has to be underlined that the PT will rather lead to a monolateral CS invasion with the normal pituitary gland displaced on the opposite site of the sella and thus "protecting" the contralateral CS. Arterial aneurysms represent lesions that can be found in the parasellar region possibly mimicking a PT. However, they are usually characterized by a strong T2-hypointensity aspect, as well as the presence of circumferential layers if coexisting thrombus of different ages is present (Fig. 3) [7]. Overall, numerous lesions can develop within or invade the CS (Table 1) and have been extensively described in their imaging features by Bonneville et al. [8].

Last, it is crucial to determine if a PT invades the CS. In MRI sequences, bulging of the lateral wall of the CS and lack of normal enhancement of the venous extrasellar spaces are suggestive of CS invasion but can be absent in case of a simple compression of the CS. Different anatomical classifications, based on MRI findings, have been proposed to specify if the CS is invaded by a PT. As an example, Knosp et al. [9] proposed that the CS is invaded if the tumor extends laterally and passes a line drawn between the cross-sectional center of the supra- and intracavernous segments of the ICA ( $\geq$ grade 2, Fig. 4 ). Cottier et al. [10] suggested that an encasement of the ICA greater than $67 \%$ makes invasion certain, while Bonneville et al. [11] suggested that an ICA remote from the sphenoid carotid sulcus is highly suggestive of CS invasion. The scenario becomes more complex when the invasion appears to be limited and when the high-quality and highresolution MRI (i.e., 3.0 T) is used. In this case, MR sequences could identify the thin internal dural membrane separating the sellar content from the CS, which usually appears as T2-hypointense line floating as a curtain between CS and the pituitary fossa.

\section{Parasellar Lesions: Who Are the Players?}

\section{Craniopharyngiomas}

Craniopharyngiomas (CPs) are rare tumors, generally showing low histological malignancy, developed from the Rathke's pouch, an invagination of the ectoderm that gives rise to the anterior pituitary gland during embryogenesis. Therefore, CPs may be located either in the sella turcica or above it (suprasellar CPs) [12]. Rarely, CPs can be ectopic, occurring in different sites such as the cerebellopontine angle, associated in a high percentage of cases with Gardner's syndrome (an autosomal dominant polyposis) [13].

As mentioned above, CPs are usually low-grade tumors (grade I WHO) burdened by low mortality, but considerable morbidity [14], currently defined into two clinicopathological variants with different phenotypes and distinctive mutations (adamantinomatous and papillary). Adamantinomatous CPs (ACPs) are composed of well-differentiated epithelium, organized in different architectural patterns: cords, lobules, nodular whorls, and irregular trabeculae surrounded by palisading columnar 

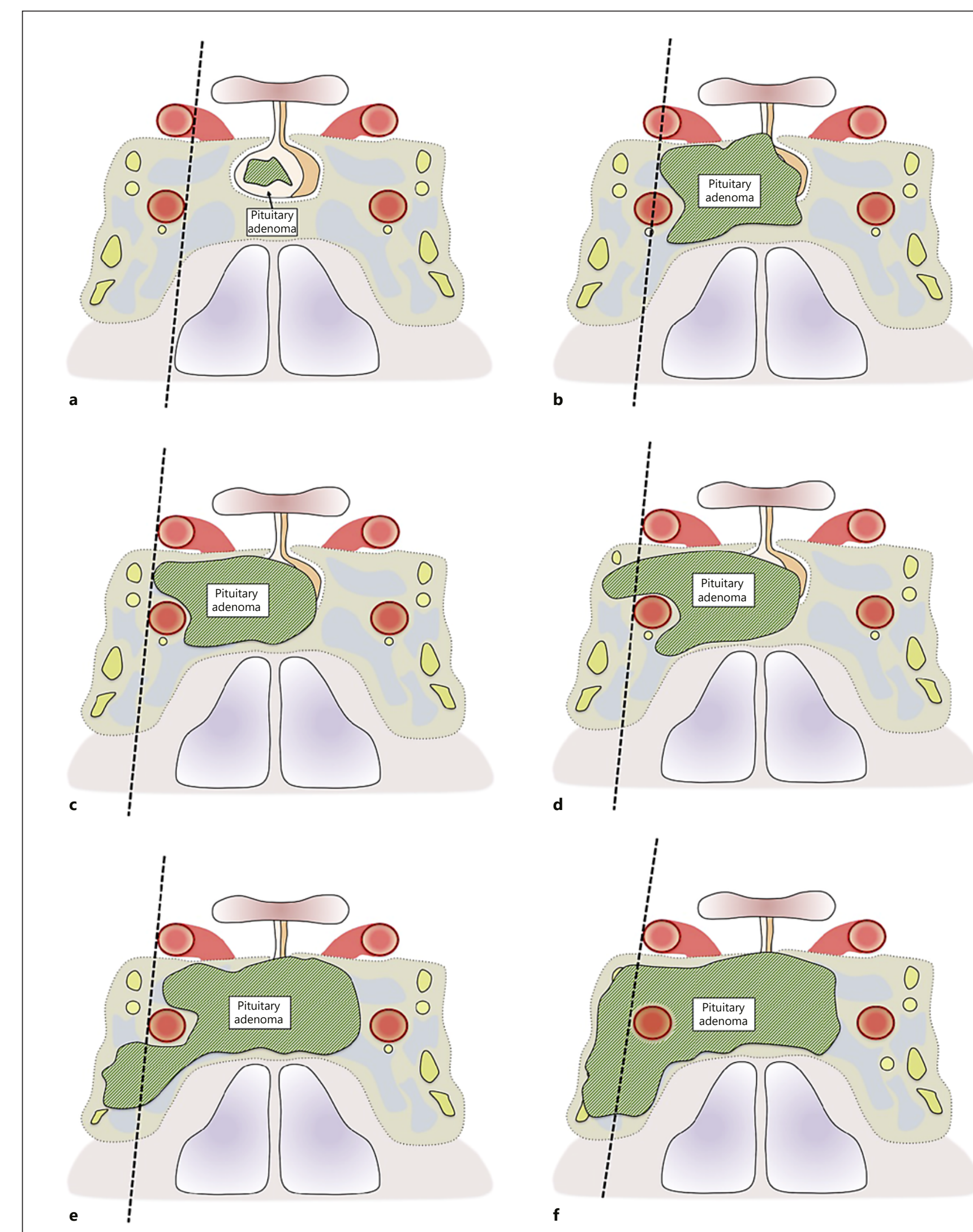

(For legend see next page.) 
epithelium. Papillary CPs (PCPs) include solid, monomorphic areas of well-differentiated squamous epithelium lacking keratinization [15]. Both histological subtypes differ in their age distribution and genesis. ACPs are diagnosed with a bimodal peak of incidence (5-15 years and 45-60 years), whereas PCPs are found only in adults, mainly in the fifth and sixth decade [12].

Overall, CPs have an incidence of $0.5-2.5$ cases per 1 million person years, representing $1.2-4.6 \%$ of all intracranial tumors [16]. Remarkably, $30-50 \%$ of CPs are diagnosed during childhood and adolescence, wherein they represent the most common non-neuroepithelial intracerebral neoplasm, accounting for 5-11\% of intracranial tumors in this specific age group [17]. In general, the overall survival in mixed pediatric and adult patient cohorts is considerably high, ranging between 54 and $96 \%$ at 5 years, 40 and $93 \%$ at 10 years, and 66 and $85 \%$ at 20 years $[18,19]$. In this context, whether age at diagnosis is a prognostic factor for survival is still a matter of debate. However, CPs are associated with long-term morbidity, mainly due to the peculiar area occupied by the lesion (parasellar region) and to tumor- and treatment-related risk factors such as progressive disease with multiple recurrences, cerebrovascular injuries, and chronic neuroendocrine deficiencies [20]. In children, a combination of symptoms, including headache, growth retardation, visual impairment and polyuria-polydipsia due to central diabetes insipidus, is highly suggestive of CP. In adults, endocrine deficiencies such as impaired sexual function, hypothalamic syndrome (i.e., disruptions in body temperature regulation and water unbalance), and clinical manifestations of increased intracranial pressure are common symptoms. MRI and computed tomography are the gold standard for the diagnosis of CP and can even guide the surgical decision according to the system developed by Puget et al. [21] (Fig. 5). However, histological confirmation is often required to set a proper treatment strategy [12]. The treatment of newly diagnosed CPs may include a combination of surgery, radiotherapy, cyst drainage, and/or intracystic interferon alpha treatment
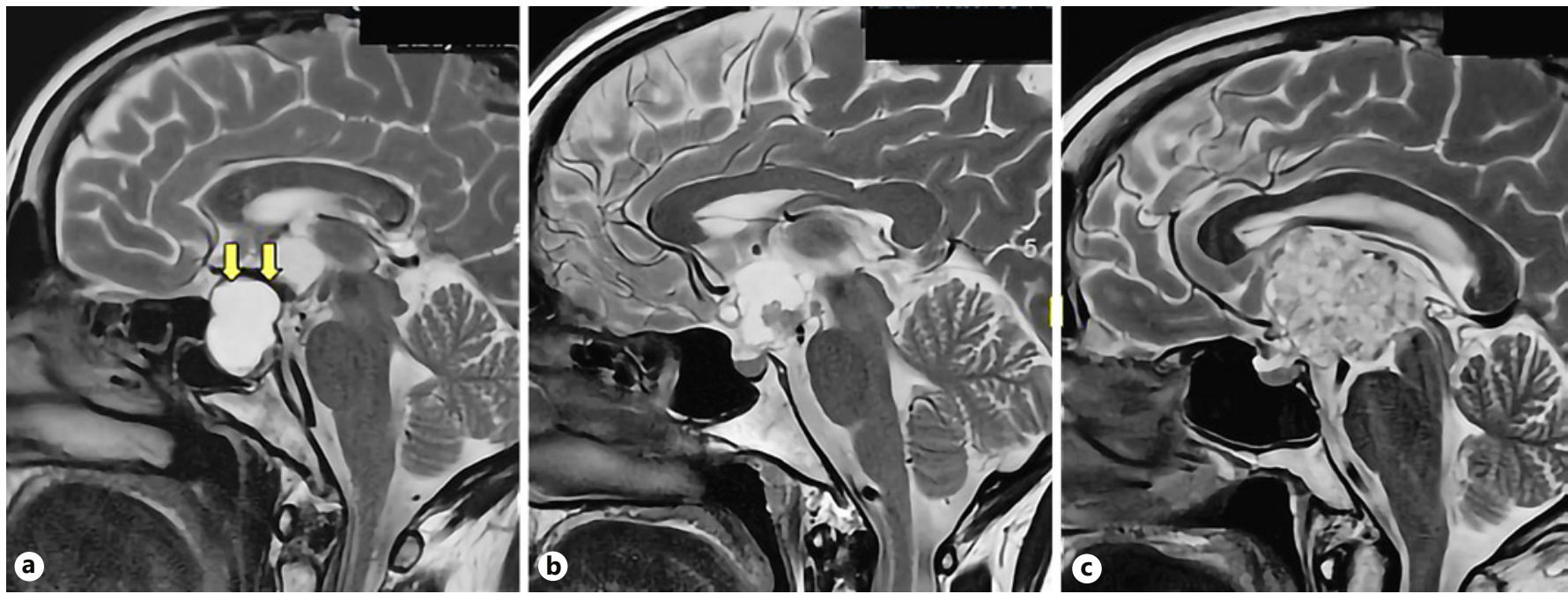

Fig. 5. Preoperative grading of craniopharyngiomas (CP) based on MRI according to Puget's system. a Grade 0 . Sagittal T2-weighted MRI of a cystic CP with no hypothalamic involvement. The third ventricle floor is normal, and the CP lies entirely below the sellar

diaphragm (arrows). b Grade 1. Sagittal T2-weighted MRI showing a $\mathrm{CP}$ which pushes the hypothalamus that can still be identified. c Grade 2. Sagittal T2-weighted MRI of CP in which the hypothalamus is unidentifiable.
Fig. 4. Knosp classification. a Grade 0 . The adenoma does not pass the medial tangent (dotted line), which passes between the medial aspects of the supra- and intracavernous portions of the ICA. b Grade 1. The adenoma passes the medial tangent but does not cross the line drawn between the cross-sectional centers of the supra- and intracavernous segments of the ICA (dotted line). c Grade 2. The adenoma extends beyond the cross-sectional line but does not pass the lateral tangent (dotted line) drawn between the lateral aspects of the supra- and intracavernous ICA. d Grade 3A. The adenoma extends beyond the lateral tangent (dotted line) and into the superior cavernous sinus compartment. e Grade 3B. The adenoma extends beyond the lateral tangent (dotted line) and into the inferior cavernous sinus compartment. f Grade 4. The adenoma completely encases the intracavernous ICA (circle). 
$[12,22]$. The management of recurrent CPs depends on the previous therapies used. Rarely, tumors may spread to the posterior fossa, causing headache, diplopia, ataxia, and hearing loss. However, incomplete resection of the tumors or regrowth of remnants result in a high recurrence rate, which translates to a high number of surgical reinterventions (21\%), additional radiotherapy (33\%), and/or hypothalamic alterations (48\%) [23].

\section{Cystic Lesions}

Cystic lesions represent a group of nosological entities, including Rathke's cleft and arachnoid, epidermoid, and dermoid cysts. Due to their peculiar location, a variety of nonspecific symptoms can be encountered, such as headache, visual field impairment, and eventually endocrine dysfunction. However, none of these symptoms is related to a particular type of cyst.

To date, MRI is the gold standard for the diagnosis of a cyst.

Rathke's cleft cysts (RCCs) represent the most frequent pituitary lesion revealed on MRI (30\% diagnosed incidentally), with a usual peak of incidence observed between 30 and 50 years of age. Since they originate from remnants of Rathke's pouch, RCCs are usually located on the midline, generally as lesion between 5 and $10 \mathrm{~mm}$ as maximum diameter $[24,25]$. On MRI, RCCs can appear as T1-hyperintense (if protein enriched RCC) or T1-hypointense lesions (if CSF-like cysts), depending on their content. A specific sign is the presence of high-protein nodules, enriched in cholesterol, that appear strongly hypointense on T2 sequences [26]. Of note, complicated RCCs generally appear as T2-hyperintense sellar mass with an increased size and more specifically a ring enhancement [27]. RCCs are typically made up of vascularized stroma of connective tissue and three types of epithelial cells: ciliated, nonciliated, and mucus-secreting epithelium. The epithelium may contain ciliated, goblet, and squamous cells. Over time, RCC can remain stable in size, enlarge slowly, shrink, or even disappear (and eventually recur). When present, the clinical picture is usually made of the combination of the following symptoms: headaches, visual disturbances and/or pituitary hormone dysfunction [27]. In cases of clinically relevant symptoms, a surgical approach is actively discussed and often performed.

Arachnoid cysts (ACs) are intra-arachnoid cystic lesions containing a liquid similar to the CSF. They are the most common type of brain cysts, representing up to 10$15 \%$ of all the parasellar lesions. Two main types of ACs are detected: primary (congenital) and secondary (post- traumatic, postinfectious). Nearby the sella turcica, we can find intrasellar ACs, which often demonstrate a suprasellar extension that displaces the pituitary stalk posteriorly, and suprasellar ACs pushing the floor of the third ventricle upward and the pituitary stalk forward [28]. ACs have similar MRI characteristics as the CSF, with spontaneous hypointense and hyperintense signal on T1 and T2 sequences, respectively. There are no solid components, absence of calcifications, and no contrast enhancement. The therapeutic strategy depends on the symptoms presented by the patient, and surgery represents a first-line treatment, if action is needed.

Epidermoid cysts (ECs) are benign lesions consisting of neuroectodermal epithelial cells, characterized by the presence of a white, pearl-like capsule, lined with stratified squamous epithelium, filled with white debris, keratin, water, and cholesterol crystals [29]. ECs are ubiquitous, but about half of intracranial ECs are located in the cerebellopontine angle. On MRI, they are T1-hypointense and show a high-T2 signal intensity (if the lipid content is not too high) [30]. As compared to ACs, ECs present with a unique irregular lobulated cauliflower-like surface [30]. The content of the dermoid cysts is a soft white material that originates from the progressive desquamation of keratin from the epithelial membrane of the cyst, sebaceous material, and dermal appendages. The presence of hair follicles and sebaceous and sweat glands in the cyst wall distinguishes dermoid cysts from epidermoid ones [31]. Dermoid cysts appear on MRI as hyperintense T1 lesions and hypointense T2 images. If the cyst is small and there are no clinical symptoms, a dynamic observation of the patient is possible. However, overall and if indicated, surgery is the only treatment.

\section{Meningiomas and Chordomas}

Meningiomas are tumors originating from arachnoid cap cells in the leptomeninges. They are considered the most common brain tumors [32] and the second most frequent parasellar neoplasms after CPs [33]. About 15\% of them develop from the parasellar region: in the CS, tuberculum sellae, diaphragm, dorsum sella, anterior and posterior clinoid processes, and the clivus. Most meningiomas are slow-growing tumors, but many of them exhibit a broad dural attachment and can encase vessels and cranial nerves, causing stenosis and nerve palsies [34]. Meningiomas are more prevalent in female patients, and their incidence increases with the age; malignant tumors are, however, more common in men and children [35, 36]. They can also occur secondary to radiotherapy performed for other malignancies $[37,38]$. 
Diagnosis is made mainly based on both neurological and radiological evaluation, although the pituitary function can be affected as well. By imaging, meningiomas appear usually as homogenous masses, hyper- or isodense compared with grey matter in CT, presenting diffuse calcification in many cases. They are isointense or occasionally hypointense on T1-weighted MRI, brightly homogeneously enhanced after gadolinium and variable in T2-weighted MRI, from isointense to hyperintense. A typical dura "tail" (an adjacent dural contrast enhancement) is frequently observed by imaging, although it is not considered a pathognomonic feature specific for meningiomas [39, 40]. Histological examination allows confirmatory diagnosis, grading, and classification. The WHO classifies meningiomas into benign (68-80\%, grade I), atypical (30-18\%, grade II), and anaplastic/malignant (2\%, grade III) [15]. Follow-up is recommended for asymptomatic patients, and surgery and radiotherapy for those presenting with mass effect symptoms. Recurrence depends on the grade and the extent of the resection, with a 5-year relapse rate ranging from $\sim 5 \%$ for grade I and $\sim 57 \%$ for grade III tumors $[41,42]$.

Chordomas are rare tumors originating from embryonic remnants of the primitive notochord. Most parasellar chordomas arise from the clivus. Because of their osteolytic activity, parasellar chordomas can invade and extend along the entire skull base, destroying the sellar space and causing visual, neurological, and endocrine problems [43]. Chordomas can be seen on CT with occasional calcifications, but MR scanning is the recommended imaging modality. On MRI, tumors are less intense than the clivus in $\mathrm{T} 1$ sequences, display heterogeneous enhancement after gadolinium contrast, and an hyperintense signal in T2-weighted images [44]. Even though most chordomas are low-grade tumors with local invasion, many patients are diagnosed in advanced stage, and metastases and long-term recurrences are not infrequent. The WHO classification consists of three groups: conventional, chondroid, and dedifferentiated. Dedifferentiation is a sign of malignancy [45]. The main treatment of chordomas is radical surgical resection, recommended together with adjuvant radiotherapy if residual tumor is detected or even suspected [46]. Long-term follow-up is needed to assess locoregional recurrence. Alternatively, radiotherapy can be applied instead of surgery. In case of confirmed skull base recurrence, high-dose radiotherapy is recommended [47]. Chordomas do not respond to conventional chemotherapy and, so far, there is no effective medical treatment [48].

Diagnosis and Treatment of Parasellar Lesions

\section{Ectopic (Parasellar) PTs}

Ectopic PTs (EPTs) are extremely rare entities, represented by PTs found outside the sella turcica, without any continuity with the intrasellar normal pituitary gland [49]. To date, approximately one hundred EPTs have been described in the literature, and available data come from single case reports or small case series. Therefore, it is extremely difficult to define a clear incidence and prevalence of these peculiar lesions among the general population.

The origin of EPTs has not been demonstrated yet. The currently accepted hypothesis suggests that these tumors originate from the proliferation of pituitary cells located along the embryological path of the pituitary development, during Rathke's pouch migration in embryogenesis [50]. The most reported locations for parasellar EPTs are sphenoid sinus, suprasellar cistern, clivus, nasopharynx, and CS [51]. Some authors suggested that EPTs are predominantly expressed in the suprasellar cistern, although most suprasellar adenomas previously considered as ectopic could have been misclassified, being "true" pituitary adenomas originating from the pars distalis or pars tuberalis of the pituitary gland (type I and type II suprasellar pituitary adenomas, respectively) [52].

Despite recent advances in imaging techniques, diagnosis of EPTs is challenging, and the great majority of cases still requires pathology validation after surgery.

Like typical intrasellar PTs, EPTs can secrete all the different hormones represented in the anterior pituitary [51], and mixed tumors (i.e., GH/PRL-secreting adenomas) have been described, as well [53].

Of note, ACTH-secreting adenomas represent the most common phenotype among the hormonally active EPTs [54, 55], followed by PRL-secreting tumors [50]. $\mathrm{GH}$ - and TSH-secreting tumors have been also described, the latter being relatively more common in EPTs compared to typical intrasellar PTs (15 vs. 1-2\%).

Clinical presentation of EPTs depends on tumor location and hormonal activity. Indeed, the peculiar hormone hypersecretion results in a specific clinical syndrome (i.e., ACTH-secreting EPTs cause Cushing's disease), while the different anatomical structures affected by the tumor mass elicit different symptoms. As an example, clival tumors most commonly present with headache and cranial neuropathy such as visual disturbances and facial paresthesia, whereas nasopharyngeal EPTs most commonly cause epistaxis and nasal congestion [56].

Interestingly, EPTs seem to exhibit a more aggressive behavior than sellar-located PTs, since a high prevalence of bone invasion and the presence of foci of necrosis at pathology evaluation are often observed [51].

Neuroendocrinology 2020;110:728-739 
To date, surgery (mainly via transsphenoidal approach) represents the treatment of choice for the majority of EPTs described in the literature. However, a preoperative hormonal assessment was not performed in most cases, and the final diagnosis was done only after the pathology report. In this light, some authors suggest to routinely perform hormone evaluation in the presence of a parasellar lesion, since this may facilitate an early diagnosis and potentially avert an unnecessary biopsy and/or surgical intervention. Indeed, in recent years, some cases of PRL-secreting EPTs have been successfully treated using medical therapy with dopamine-agonists [50], and both GH- and TSH-secreting ETPs are supposed to benefit from treatment with somatostatin receptor ligands [57-59].

\section{New Molecular Actors in the Pathophysiology of Parasellar Lesions}

Over the past years, substantial progress has been made in the understanding of parasellar lesions, especially in the field of CPs and meningiomas/chordomas. ACPs have been proposed to be of embryonic origin based on molecular and histological features [60], and recent genomic studies demonstrated that $\sim 90 \%$ of ACPs harbor somatic mutations in the CTNNB1 gene, which increases $\beta$-catenin stability and activation of the WNT pathway [61]. In contrast, PCPs are typically noncalcified, solid tumors that frequently harbor somatic $B R A F^{\mathrm{V} 600 \mathrm{E}}$ mutations that result in the activation of the MAPK signaling pathway [61]. To date, only few case reports demonstrated a sustained efficacy of the combination treatment with trametinib (MEK inhibitor) and dabrafenib (BRAF inhibitor) in patients with recurrent PCPs [62]. This significant progress has paved the way for a phase II clinical trial using a combination of vemurafenib and cometinib in patients with PCP (NCT03224767). Recent experimental data suggest that the MAP kinase pathway could also play a key role in the development of ACPs, particularly affecting tumor invasiveness (the so-called "palisaded epithelium" compartment of ACPs) [63].

Meningiomas occasionally occur in the context of familial diseases, such as neurofibromatosis type 2 (NF2) and multiple endocrine neoplasia type 1 . In sporadic cases, about $50 \%$ harbor mutations in NF2 or loss of this locus at chromosome 22q, and they are enriched in highgrade meningiomas [64]. In contrast, low-grade meningiomas are commonly mutated in TRAF7 ( $20 \%$ cases),
AKT1 ( 10\%), PIK3CA ( 7\%), SMO ( 6\%), POLR2A (6\%), SUFU, SMARCB1, KLF4, AKT3 and BAP1 (all of them <1\%) [65, 66], with TRAF7, AKT1, and KLF4 mutations being common in meningiomas of the parasellar region. Of interest, some of these genes are therapeutic targets of drugs such as alpelisib, vismodegib, or ipatasertib. In addition, genetic variants in the promoter region of the telomerase reverse transcriptase (TERT) gene have been suggested as markers of malignant progression and shorter progression-free survival in meningiomas [6769].

Expression of the transcription factor Brachyury $(T)$ is a hallmark of chordomas and represents a useful marker to discriminate between these tumors and other skull base lesions. Indeed, $T$ is overexpressed and duplicated in $\sim 20-30 \%$ of sporadic cases of chordomas [70, 71]. Recurrent somatic mutations are rare in chondromas. A recent report has shown truncating mutations in the lysosomal trafficking regulator LYST in 5/67 (6\%) cases [71]. CD$K N 2 A$ deletions (with or without loss of CDKN2B) account for $\sim 30-80 \%$ cases, mainly homozygosis [72], providing the rationale for clinical trials with palbociclib, a CDK4/6 inhibitor (www.clinicaltrials.gov; NCTPMO-1601). Mutations in the SWI/SNF, TP53, and PIK3CA pathways are frequent as well $[71,73]$ and are under consideration for targeted treatments.

\section{Conclusions}

The parasellar region can be the preferential site for the development of several lesions of different origins. Therefore, clinicians will have to deal with two major concerns: does the lesion develop from the sella turcica and extend laterally to the parasellar region or does it primarily arise from parasellar anatomical structures (this latter point already providing some information about the potential nature of the lesion)? Furthermore, in case of a sellar lesion, can we assume, based on MR imaging, that CS is invaded? Biochemical and hormonal evaluation as well as visual assessment will help to clarify the nature of the lesion, especially if an overt hypersecretion of an anterior pituitary hormone is detected. The features of the lesion on MRI have to be evaluated and described with a systematic approach, requiring a skilled neuroradiology team. The role of the neuroradiologist appears of upmost importance given the complexity of the parasellar region and the existence of several imaging pitfalls such as partial volume artefacts (which occur when a thick MRI section includes different anatomical 
structure and the computer calculates the intensity average of the different components which can simulate a PT), magnetic susceptibility artefacts (i.e., localized signal intensity changes at the interface of anatomical structures of different signal intensities, responsible for geometrical distortions), chemical shifts artefacts (consequence of the high signal of fat, which can be avoided by fat saturation sequences), and eventually flow artefacts [8]. Among all the lesions that can be found in the parasellar region, invading PTs and meningiomas are those most commonly encountered in clinical practice. Different treatment strategies need to be actively discussed, since surgery (usually the first-line treatment) can be limited due to the proximity of vital structures (i.e., ICA or cranial nerves within the CS). Recent studies have identified gene mutations or signaling pathway modulations that can confer parasellar lesions a more aggressive behavior (i.e., higher invasiveness of the surrounding structures) [63, 74-76] and, therefore, could represent potential candidates for the development of targeted therapies.

\section{Acknowledgement}

The authors acknowledge Prof. Jean-François Bonneville for providing illustrations in the article.

\section{Statement of Ethics} article.

All patients gave their written consent for images used in the

\section{Disclosure Statement}

We declare no competing interests.

\section{Funding Sources}

There was no funding supporting this article.

\section{Author Contributions}

All coauthors contributed equally to the redaction of the manuscript. F.G. and T.C. reviewed and revised it. All coauthors approved the final submitted version.

\section{References}

1 Ruscalleda J. Imaging of parasellar lesions. Eur Radiol. 2005 Mar;15(3):549-59.

2 Kaltsas GA, Evanson J, Chrisoulidou A, Grossman $\mathrm{AB}$. The diagnosis and management of parasellar tumours of the pituitary. Endocr Relat Cancer. 2008 Dec;15(4):885903.

3 Choe $\mathrm{CH}$, Cornblath WT. Orbital signs of parasellar syndromes. In: Black EH, Nesi FA, Calvano CJ, Gladstone GJ, Levine MR, editors. Smith and Nesi's Ophthalmic Plastic and Reconstructive Surgery. 3rd ed. Berlin: Springer; 2012. p. 759-778.

4 Rhoton AL Jr. The cavernous sinus, the cavernous venous plexus, and the carotid collar. Neurosurgery. 2002 Oct;51(4 Suppl): S375-410.

5 Cappabianca P, Cavallo LM, Esposito F, De Divitiis O, Messina A, De Divitiis E. Extended endoscopic endonasal approach to the midline skull base: the evolving role of transsphenoidal surgery. Adv Tech Stand Neurosurg. 2008;33:151-99.

6 Go JL, Rajamohan AG. Imaging of the Sella and Parasellar Region. Radiol Clin North Am. 2017 Jan;55(1):83-101.

7 Hanak BW, Zada G, Nayar VV, Thiex R, Du $\mathrm{R}$, Day AL, et al. Cerebral aneurysms with intrasellar extension: a systematic review of clinical, anatomical, and treatment characteristics. J Neurosurg. 2012 Jan;116(1):164-78.

8 Bonneville JF, Bonneville F, Cattin F, Nagi S. MRI of the Pituitary Gland. Berlin: Springer; 2016.
9 Knosp E, Steiner E, Kitz K, Matula C. Pituitary adenomas with invasion of the cavernous sinus space: a magnetic resonance imaging classification compared with surgical findings. Neurosurgery. 1993 Oct;33(4):610-7.

10 Cottier JP, Destrieux C, Brunereau L, Bertrand P, Moreau L, Jan M, et al. Cavernous sinus invasion by pituitary adenoma: MR imaging. Radiology. 2000 May;215(2):463-9.

11 Bonneville JF, Cattin F, Racle A, Bouchareb M, Boulard D, Potelon P, et al. Dynamic CT of the laterosellar extradural venous spaces [Internet]. AJNR Am J Neuroradiol. 1989 May-Jun;10(3):535-42. [cited 2020 Jan 29].

12 Müller HL, Merchant TE, Warmuth-Metz M, Martinez-Barbera JP, Puget S. Craniopharyngioma. Nat Rev Dis Primers. 2019 Nov;5(1): 75.

13 Gabel BC, Cleary DR, Martin JR, Khan U, Snyder V, Sang U H. Unusual and Rare Locations for Craniopharyngiomas: Clinical Significance and Review of the Literature. World Neurosurg. 2017 Feb;98:381-7.

14 Mende KC, Kellner T, Petersenn S, Honegger J, Evangelista-Zamora R, Droste M, et al. Clinical Situation, Therapy, and Follow-Up of Adult Craniopharyngioma. J Clin Endocrinol Metab. 2020 Jan;105(1):dgz043.

15 Louis DN, Perry A, Reifenberger G, von Deimling A, Figarella-Branger D, Cavenee WK, et al. The 2016 World Health Organization Classification of Tumors of the Central Nervous System: a summary. Acta Neuropathol. 2016 Jun;131(6):803-20.
16 Zacharia BE, Bruce SS, Goldstein H, Malone HR, Neugut AI, Bruce JN. Incidence, treatment and survival of patients with craniopharyngioma in the surveillance, epidemiology and end results program. Neuro-oncol. 2012 Aug;14(8):1070-8.

17 Olsson DS, Andersson E, Bryngelsson IL Nilsson AG, Johannsson G. Excess mortality and morbidity in patients with craniopharyngioma, especially in patients with childhood onset: a population-based study in Sweden. J Clin Endocrinol Metab. 2015 Feb;100(2): $467-74$.

18 Karavitaki N, Brufani C, Warner JT, Adams CB, Richards P, Ansorge O, et al. Craniopharyngiomas in children and adults: systematic analysis of 121 cases with long-term followup. Clin Endocrinol (Oxf). 2005 Apr;62(4): 397-409.

19 Pemberton LS, Dougal M, Magee B, Gattamaneni HR. Experience of external beam radiotherapy given adjuvantly or at relapse following surgery for craniopharyngioma. Radiother Oncol. 2005 Oct;77(1):99-104.

20 Wijnen $M$, van den Heuvel-Eibrink MM, Janssen JA, Catsman-Berrevoets CE, Michiels $\mathrm{EM}$, van Veelen-Vincent MC, et al. Very long-term sequelae of craniopharyngioma. Eur J Endocrinol. 2017 Jun;176(6):755-67.

21 Puget S, Garnett M, Wray A, Grill J, Habrand $\mathrm{JL}$, Bodaert N, et al. Pediatric craniopharyngiomas: classification and treatment according to the degree of hypothalamic involvement. J Neurosurg. 2007 Jan;106(1 Suppl):3-12. 
22 Müller HL. Craniopharyngioma. Endocr Rev. 2014 Jun;35(3):513-43.

23 Sterkenburg AS, Hoffmann A, Gebhardt U, Warmuth-Metz M, Daubenbüchel AM, Müller HL. Survival, hypothalamic obesity, and neuropsychological/psychosocial status after childhood-onset craniopharyngioma: newly reported long-term outcomes. Neuro-oncol. 2015 Jul;17(7):1029-38.

24 Larkin S, Karavitaki N, Ansorge O. Rathke's cleft cyst. Handb Clin Neurol. 2014;124:25569.

25 Osborn AG, Preece MT. Intracranial cysts: radiologic-pathologic correlation and imaging approach. Radiology. 2006 Jun;239(3): 650-64.

26 Wang S, Nie Q, Wu Z, Zhang J, Wei L. MRI and pathological features of Rathke cleft cysts in the sellar region. Exp Ther Med. 2020 Jan; 19(1):611-8.

27 Trifanescu R, Ansorge O, Wass JA, Grossman $\mathrm{AB}$, Karavitaki N. Rathke's cleft cysts. Clin Endocrinol (Oxf). 2012 Feb;76(2):151-60.

28 Dubuisson AS, Stevenaert A, Martin DH, Flandroy PP. Intrasellar arachnoid cysts. Neurosurgery. 2007 Sep;61(3):505-13.

29 Ravindran K, Rogers TW, Yuen T, Gaillard F. Intracranial white epidermoid cyst with dystrophic calcification - A case report and literature review. J Clin Neurosci. 2017 Aug;42: 43-7.

30 Ren X, Lin S, Wang Z, Luo L, Jiang Z, Sui D, et al. Clinical, radiological, and pathological features of 24 atypical intracranial epidermoid cysts. J Neurosurg. 2012 Mar;116(3) 611-21.

31 Choi JS, Bae YC, Lee JW, Kang GB. Dermoid cysts: epidemiology and diagnostic approach based on clinical experiences. Arch Plast Surg. 2018 Nov;45(6):512-6.

32 Ostrom QT, Gittleman H, Truitt G, Boscia A Kruchko C, Barnholtz-Sloan JS. CBTRUS statistical report: primary brain and other central nervous system tumors diagnosed in the United States in 2011-2015. Neuro Oncol, 2018 Oct;20 suppl_4:iv1-86.

33 Famini P, Maya MM, Melmed S. Pituitary magnetic resonance imaging for sellar and parasellar masses: ten-year experience in 2598 patients. J Clin Endocrinol Metab. 2011 Jun; 96(6):1633-41.

34 Zada G, Lopes MB, Mukundan S, Laws E. Meningioma of the Sellar and Parasellar Region. Atlas of Sellar and Parasellar Lesions. Cham: Springer International Publishing; 2016. pp. 259-69.

35 Islim AI, Mohan M, Moon RD, Srikandarajah $\mathrm{N}$, Mills SJ, Brodbelt AR, et al. Incidental intracranial meningiomas: a systematic review and meta-analysis of prognostic factors and outcomes. J Neurooncol. 2019 Apr;142(2) 211-21.

36 Grossbach AJ, Mahaney KB, Menezes AH. Pediatric meningiomas: 65-year experience at a single institution. J Neurosurg Pediatr. 2017 Jul;20(1):42-50.
37 Lee JW, Wernicke AG. Risk and survival outcomes of radiation-induced CNS tumors. J Neurooncol. 2016 Aug;129(1):15-22.

38 Agnihotri S, Suppiah S, Tonge PD, Jalali S, Danesh A, Bruce JP, et al. Therapeutic radiation for childhood cancer drives structural aberrations of NF2 in meningiomas. Nat Commun. 2017 Aug;8(1):186.

39 Huang RY, Bi WL, Griffith B, Kaufmann TJ, la Fougère $\mathrm{C}$, Schmidt $\mathrm{NO}$, et al. Imaging and diagnostic advances for intracranial meningiomas. Neuro Oncol. 2019 Jan;21(Suppl 1):i44-61.

40 Huang RY, Bi WL, Griffith B, Kaufmann TJ, la Fougère C, Schmidt NO, et al.; International Consortium on Meningiomas. Imaging and diagnostic advances for intracranial meningiomas. Neuro-oncol. 2019 Jan;21 Supplement_1:i44-61.

41 Pessina F, Navarria P, Clerici E, Soffietti R, Nibali MC, Rudà R, et al. Intracranial Meningiomas: A Systematic Analysis of Prognostic Factors for Recurrence in a Large Single Institution Surgical Series. World Neurosurg. 2019 Mar;123:e273-9.

42 Goldbrunner R, Minniti G, Preusser M, Jenkinson MD, Sallabanda K, Houdart E, et al. EANO guidelines for the diagnosis and treatment of meningiomas. Lancet Oncol. 2016 Sep;17(9):e383-91.

43 Zoli M, Milanese L, Bonfatti R, Faustini-Fustini M, Marucci G, Tallini G, et al. Clival chordomas: considerations after 16 years of endoscopic endonasal surgery. J Neurosurg. 2018 Feb;128(2):329-38.

44 Asioli S, Zoli M, Guaraldi F, Sollini G, Bacci A, Gibertoni D, et al. Peculiar pathological, radiological and clinical features of skull base dedifferentiated chordomas. Results from a referral Center case series and literature review. Histopathology. 2019. doi:10.1111/ his. 14024 .

45 Shih AR, Chebib I, Deshpande V, Dickson BC, Iafrate AJ, Nielsen GP. Molecular characteristics of poorly differentiated chordoma. Genes Chromosomes Cancer. 2019 Nov; 58(11):804-808

46 Stacchiotti S, Sommer J; Chordoma Global Consensus Group. Building a global consensus approach to chordoma: a position paper from the medical and patient community. Lancet Oncol. 2015 Feb;16(2):e71-83.

47 Stacchiotti S, Gronchi A, Fossati P, Akiyama T, Alapetite C, Baumann M, et al. Best practices for the management of local-regional recurrent chordoma: a position paper by the Chordoma Global Consensus Group. Ann Oncol. 2017 Jun;28(6):1230-42.

48 Colia V, Stacchiotti S. Medical treatment of advanced chordomas. Eur J Cancer. 2017 Sep; 83:220-8.

49 Guerrero CA, Krayenbühl N, Husain M, Krisht AF. Ectopic suprasellar growth hormone-secreting pituitary adenoma: case report. Neurosurgery. 2007 Oct;61(4):E879.
50 Agely A, Okromelidze L, Vilanilam GK, Chaichana KL, Middlebrooks EH, Gupta V. Ectopic pituitary adenomas: common presentations of a rare entity. Pituitary. 2019 Aug; 22(4):339-43.

51 Shuman W, Loewenstern J, Pai A, Bederson J, Shrivastava R. Variability in Clinical Presentation and Pathologic Implications of Ectopic Pituitary Tumors: Critical Review of Literature. World Neurosurg. 2019 Feb;122:397403

52 Zhou HJ, Pan DS, Ba XQ, Zhan RY, Zheng XJ, $\mathrm{Ma}$ YH. 'Ectopic' suprasellar type IIa PRL-secreting pituitary adenoma. Pituitary. 2017 Aug;20(4):477-84.

53 Bobeff EJ, Wiśniewski K, Papierz W, Stefańczyk L, Jaskólski DJ. Three cases of ectopic sphenoid sinus pituitary adenoma. Folia Neuropathol. 2017;55(1):60-6.

54 Pluta RM, Nieman L, Doppman JL, Watson JC, Tresser N, Katz DA, et al. Extrapituitary parasellar microadenoma in Cushing's disease. J Clin Endocrinol Metab. 1999 Aug; 84(8):2912-23.

55 Zhu J, Lu L, Yao Y, Chen S, Li W, You H, et al. Long-term follow-up for ectopic ACTHsecreting pituitary adenoma in a single tertiary medical center and a literature review. Pituitary. 2020 Apr;23(2):149-159.

56 Thompson LD, Seethala RR, Müller S. Ectopic sphenoid sinus pituitary adenoma (ESSPA) with normal anterior pituitary gland: a clinicopathologic and immunophenotypic study of 32 cases with a comprehensive review of the english literature. Head Neck Pathol. 2012 Mar;6(1):75-100.

57 Ortiz E, Peldoza M, Monnier E, Gejman R, Henriquez M, Barra MI, et al. Ectopic pituitary adenoma of the TSH-secreting sphenoidal sinus with excellent response to somatostatin analogs. Theory of the embryogenesis and literature review from a clinical case. Steroids. 2020 Feb;154:108535.

58 Tong A, Xia W, Qi F, Jin Z, Yang D, Zhang Z, et al. Hyperthyroidism caused by an ectopic thyrotropin-secreting tumor of the nasopharynx: a case report and review of the literature. Thyroid. 2013 Sep;23(9):1172-7.

59 Ramírez C, Hernández-Ramirez LC, Espinosa-de-los-Monteros AL, Franco JM, Guinto G, Mercado M. Ectopic acromegaly due to a $\mathrm{GH}$-secreting pituitary adenoma in the sphenoid sinus: a case report and review of the literature. BMC Res Notes. 2013 Oct;6(1):411.

60 Buslei R, Nolde M, Hofmann B, Meissner S, Eyupoglu IY, Siebzehnrübl F, et al. Common mutations of $\beta$-catenin in adamantinomatous craniopharyngiomas but not in other tumours originating from the sellar region. Acta Neuropathol. 2005 Jun;109(6):589-97.

61 Brastianos PK, Taylor-Weiner A, Manley PE, Jones RT, Dias-Santagata D, Thorner AR, et al. Exome sequencing identifies BRAF mutations in papillary craniopharyngiomas. Nat Genet. 2014 Feb;46(2):161-5. 
62 Gupta S, Bi WL, Giantini Larsen A, Al-Abdulmohsen S, Abedalthagafi M, Dunn IF. Craniopharyngioma: a roadmap for scientific translation. Neurosurg Focus. 2018 Jun; 44(6):E12.

63 Apps JR, Carreno G, Gonzalez-Meljem JM, Haston S, Guiho R, Cooper JE, et al. Tumour compartment transcriptomics demonstrates the activation of inflammatory and odontogenic programmes in human adamantinomatous craniopharyngioma and identifies the MAPK/ERK pathway as a novel therapeutic target. Acta Neuropathol. 2018 May;135(5): 757-77.

64 Bi WL, Mei Y, Agarwalla PK, Beroukhim R, Dunn IF. Genomic and Epigenomic Landscape in Meningioma. Neurosurg Clin N Am. 2016 Apr;27(2):167-79.

65 Clark VE, Erson-Omay EZ, Serin A, Yin J, Cotney J, Özduman K, et al. Genomic analysis of non-NF2 meningiomas reveals mutations in TRAF7, KLF4, AKT1, and SMO. Science. 2013 Mar;339(6123):1077-80.

66 Clark VE, Harmancı AS, Bai H, Youngblood MW, Lee TI, Baranoski JF, et al. Recurrent somatic mutations in POLR2A define a distinct subset of meningiomas. Nat Genet. 2016 Oct; 48(10):1253-9.
67 Biczok A, Jungk C, Egensperger R, von Deimling A, Suchorska B, Tonn JC, et al. Microscopic brain invasion in meningiomas previously classified as WHO grade I is not associated with patient outcome. J Neurooncol. 2019 Dec;145(3):469-77.

68 Goutagny S, Nault JC, Mallet M, Henin D, Rossi JZ, Kalamarides M. High incidence of activating TERT promoter mutations in meningiomas undergoing malignant progression. Brain Pathol. 2014 Mar;24(2):184-9.

69 Brastianos PK, Horowitz PM, Santagata S, Jones RT, McKenna A, Getz G, et al. Genomic sequencing of meningiomas identifies oncogenic SMO and AKT1 mutations. Nat Genet. 2013 Mar;45(3):285-9.

70 Bell D, Raza SM, Bell AH, Fuller GN, DeMonte F. Whole-transcriptome analysis of chordoma of the skull base. Virchows Arch. 2016 Oct;469(4):439-49.

71 Tarpey PS, Behjati S, Young MD, Martincorena I, Alexandrov LB, Farndon SJ, et al. The driver landscape of sporadic chordoma. Nat Commun. 2017 Oct;8(1):890.
72 Hallor KH, Staaf J, Jönsson G, Heidenblad M, Vult von Steyern F, Bauer HC, et al. Frequent deletion of the CDKN2A locus in chordoma: analysis of chromosomal imbalances using array comparative genomic hybridisation. $\mathrm{Br}$ J Cancer. 2008 Jan;98(2):434-42.

73 Le LP, Nielsen GP, Rosenberg AE, Thomas D, Batten JM, Deshpande V, et al. Recurrent chromosomal copy number alterations in sporadic chordomas. PLoS One. 2011; 6(5):e18846.

74 Zubeldía-Brenner L, De Winne C, Perrone S, Rodríguez-Seguí SA, Willems C, Ornstein $\mathrm{AM}$, et al. Inhibition of Notch signaling attenuates pituitary adenoma growth in Nude mice. Endocr Relat Cancer. 2019 Jan;26(1): 13-29.

75 Barry S, Carlsen E, Marques P, Stiles CE, Gadaleta E, Berney DM, et al. Tumor microenvironment defines the invasive phenotype of AIP-mutation-positive pituitary tumors. Oncogene. 2019 Jul;38(27):5381-95.

76 Marques P, Barry S, Carlsen E, Collier D, Ronaldson A, Awad S, et al. Chemokines modulate the tumour microenvironment in pituitary neuroendocrine tumours. Acta Neuropathol Commun. 2019 Nov;7(1):172. 